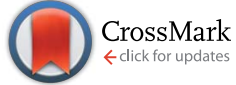

Cite this: J. Anal. At. Spectrom., 2015 30,738

Received 31st October 2014 Accepted 15th January 2015

DOI: $10.1039 / c 4 j a 00382 a$

www.rsc.org/jaas

\section{A comparative study of Hispano-Moorish and Italian Renaissance lustred majolicas by using X-ray absorption spectroscopy}

\begin{abstract}
C. Guglieri Rodriguez, ${ }^{\text {b }}$ P. Fermo, ${ }^{c}$ L. Olivi ${ }^{b}$ and G. Padeletti ${ }^{\star a}$
Lustre is characterized by a few hundreds of nanometers thick heterogeneous metal-glassy nanocomposite film. Silver and copper nanoparticles are dispersed within the outermost layers of the glaze, conferring peculiar optical properties to the whole material. Even though numerous studies have been carried out, many questions regarding the chemical composition, the mechanism of metal reduction and the optical properties of lustre still remain. Synchrotron radiation techniques are suitable for detailed studies on metal-glassy nano-composites. For example, X-ray absorption fine structure spectroscopy (EXAFS) can provide useful information on oxidized phases or atomic clusters dispersed in an amorphous medium, otherwise not achievable with diffraction techniques. In this work, we try to get information on the chemical state and local environment of metal atoms in the lustre and in the blue pigment, in order to achieve a better understanding of the reduction mechanism of different metals present and the manufacturing techniques related to different productions (Hispano-Moorish and Italian Renaissance lustred majolicas). In particular, different samples characterized by lustre and blue decorations only, produced in Spain and in central Italy in XIV-XV cent., are compared.
\end{abstract}

\section{Introduction}

Lustre was one of the most sophisticated techniques for the decoration of majolicas during the Renaissance period. Lustre consists of a thin metallic film containing silver, copper and other substances, like iron oxide and cinnabar, applied in a reducing atmosphere on a previously glazed ceramic. In this way, beautiful iridescent reflections of different colours (in particular gold and ruby-red) are obtained. ${ }^{1-17}$ The characterisation and the study of lustre decorated majolicas is of considerable interest for archaeologists and scientists, offering possibilities to produce pottery with outstanding decoration following ancient examples, because nowadays artisans are interested in the reproduction of ancient recipes and procedures. The lustre technique, originally developed in Iraq, later spread to Egypt, Persia and Spain, following the expansion of the Arabian culture during medieval time. From Spain (Valencia, Manises and Malaga), lustre was introduced in the Italian peninsula, mostly in central Italy where it was used to decorate the most beautiful majolicas. Gubbio and Deruta, located in the Umbria region, were important centres for this activity. It has to be pointed out that the Italian

${ }^{a}$ ISMN-CNR Area della Ricerca Roma1, via Salaria km 29.5, o0015 Monterotondo, RM, Italy. E-mail: giuseppina.padeletti@cnr.it

${ }^{b}$ Elettra Sicrotrone Trieste, Strada Statale $14-\mathrm{km} 163.5$ in AREA Science Park, Basovizza, 34149 Trieste, Italy

'Dip. Chimica, Università di Milano, via Golgi, 19, 20133 Milano, Italy artisans developed their own style, for the decorative motifs, as well as for what concerns the metallic colours obtained. For this reason, the local artisans became keepers of refined and secret recipes and techniques for decorating ceramic objects. Mastro Giorgio Andreoli da Gubbio was the most important artist in this field, whose works can be found in the most important museums of the world and are very well known in the antique trade market, as well. ${ }^{22-24}$ His fame is due to the fact that optimising the lustre technique, he obtained outstanding results that were not possible to replicate during his time, and even at present. He was specialised mainly in two kinds of reflects: an intense golden-yellow and a ruby-red colour. The original recipes and technological procedures used at that time, were and remained a secret after his death and until today.

In the specific case of the Renaissance period, information on the majolica production technology were passed on by the Knight Cipriano Piccolpasso from Casteldurante, who wrote a treatise entitled "The three books on the art of the Potter" (1558). However, the information reported by Piccolpasso could not be entirely correct, due to the aforementioned reasons regarding the secrecy. From his information, the objects were obtained in the desired form and fired in a first step at $1000{ }^{\circ} \mathrm{C}$. Once cooked and cooled down, the object was immersed in the glaze constituted by sand, potassium carbonate, salts and oxides, such as lead and tin oxides, finely ground and mixed with water. After drying in air, it was possible to decorate the glazed surface by using very soft 
brushes, made by the bristles of goat, and sometimes, for very fine details, whiskers of cats and mice, too. Following this and after spraying with a transparent paint, the object underwent a second firing at $900{ }^{\circ} \mathrm{C}$. At the end of this process, the object was complete. However, if we refer to lustre, another step was required to achieve the result of producing reflections and iridescence on majolica. Ancient documentation indicates that the lustre was obtained using a mixture of copper and silver salts, clays, ochre and other optional substances, dissolved or dispersed in vinegar and firing it in a reducing atmosphere at about $600{ }^{\circ} \mathrm{C}$ in special kilns made for this purpose, where probably it was easier to control both the temperature and the atmosphere.

Lustre decoration in Italian and Hispano-Moorish majolicas has been characterized by numerous analytical techniques. Today it is well known that the lustre films are formed by copper and silver clusters of nanometric dimensions. The colour and the properties of the lustre films depend on the elemental composition of the impasto applied on the ceramic surface, as well as on other factors like the metallic nanocluster dimensions, the firing conditions, the underlying glaze composition and the procedures used. ${ }^{1-9}$ Regarding possible differences between both productions, it has been found that Italian artisans also added bismuth to the impasto for preparing the lustre, probably in order to keep down the cost. In fact the cosalite phase $\left(\mathrm{Pb}_{2} \mathrm{Bi}_{2} \mathrm{~S}_{5}\right)$ has been disclosed in the Italian lustres and it can be considered as a marker, which allows us to attribute an object of uncertain provenance to the Italian production. $^{25-30}$

In order to obtain a deeper knowledge of the differences between the two different productions, X-ray absorption spectroscopy (XAS) was used, which is a powerful tool allowing the determination of the local environment around a selected atomic species. To date, some studies have been carried by XAS on gold and red lustre, both of Italian and Hispanic provenance. ${ }^{18-21}$ Even if the oxidation state of copper and silver has been studied extensively, blue decorations on lustre samples have not yet been investigated in depth.

In this work, a XAS study has been carried out to get information on the chemical state and on the local environment of metal atoms in the glaze, lustre and blue pigment. For this reason, samples produced in Spain and central Italy in XIV-XV centuries were compared, with the aim to achieve a better understanding of the technological processes and materials used in different productions.

\section{Experimental}

Two samples have been chosen to investigate possible differences in the coordination state and local environment of metal atoms constituting the blue pigment and the lustre in Italian and Hispano-Moorish productions. The sample L19 represents a typical Italian Renaissance production, from central Italy, and LIM1, one of Hispano-Moorish lustre. Both fragments are in very good conservation state, never restored or treated. The two samples were given to us by Gubbio Town Council Museum and classified by experts as original shards. In particular, both shards were already the objects of archaeometric investiga-

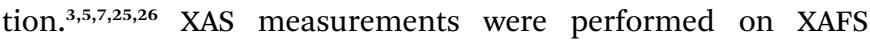
beamline, installed on a bending magnet source, at Elettra Sincrotrone Trieste. ${ }^{31}$ The storage ring energy was operated at $2.4 \mathrm{GeV}$ with a ring current of $159 \mathrm{~mA}$. A Si (111) double-crystal monochromator was used to monochromatize the white beam, and higher harmonics were rejected by detuning the Bragg's angle of the second crystal. The beam size was set at $1 \times 1 \mathrm{~mm}^{2}$ and the photon flux was about $10^{10}$ photons per s. All spectra were collected at fluorescence mode, with a Silicon Drift Detector.

In addition several references $\left(\mathrm{CoO}, \mathrm{Co}_{3} \mathrm{O}_{4}, \mathrm{NiO}\right.$, metallic $\mathrm{Cu}$, $\mathrm{CuO}$ and $\mathrm{Cu}_{2} \mathrm{O}$ ) were measured in transmission mode. The spectra were recorded at both the X-ray Absorption Near Edge Structure (XANES) and the Extended X-Ray Absorption Fine Structure (EXAFS) regions.

The analyses were performed according to standard procedures. ${ }^{32}$ XAS spectra were normalized, after background subtraction, to the averaged absorption coefficient at high energy. EXAFS signals $(k)$ were extracted from the spectra by using the Athena software, ${ }^{33}$ removing the background by a cubic spline polynomial fitting and normalising the magnitude of the oscillations to the edge jump. The corresponding pseudoradial distribution function around the photoabsorbing atom has been obtained by performing the Fourier transform, FT (using a sine window). The fitting to the experimental data was carried out in both R-space and q-space, by using the programme Artemis, also within the IFEFFIT package. $^{33}$

The study was focused on Hispano-Moorish LIM1 and Italian L19 samples dated back to XIV-XV cent. XANES and EXAFS spectra were recorded at the Co K-edge (7709 eV), Ni K-edge $(8333 \mathrm{eV})$ and $\mathrm{Cu} \mathrm{K}$-edge $(8979 \mathrm{eV})$ in the blue pigmented regions of the pottery, and at the $\mathrm{Cu}$ K-edge at the lustre. The FT of the EXAFS signals were filtered in the interval $k=2.5 \leq k \leq$ $11.7 \AA^{-1}, k=2.3 \leq k \leq 8.8 \AA^{-1}$ and $k=2.5 \leq k \leq 10.7 \AA^{-1}$ for the $\mathrm{Co}, \mathrm{Ni}$ and $\mathrm{Cu}$ K-edge, respectively.

SEM-EDX data were acquired on thin sections obtained starting from cross-sections prepared after embedding the shards into a suitable resin. The instrument used was a Hitachi TM1000 equipped with an energy dispersive X-ray Spectrometer (Oxford Instruments SwiftED).

\section{Results and discussion}

\section{SEM measures on the blue pigment}

The SEM images acquired on the two thin sections of the samples LIM1 and L19, are shown in Fig. 1. At a first glance, it is evident that the Hispano-Moorish sample shows a glaze, which is more homogeneous with respect to the Italian one. Furthermore, the glaze thickness in LIM1 is lower (about $100 \mu \mathrm{m}$ ) with respect to that of the Italian lustre (between 160 and $180 \mu \mathrm{m}$ ). EDS analyses (not shown) evidenced the presence of iron, cobalt and nickel in the blue parts, in accordance with what was previously observed for the blue colour. ${ }^{3}$ 


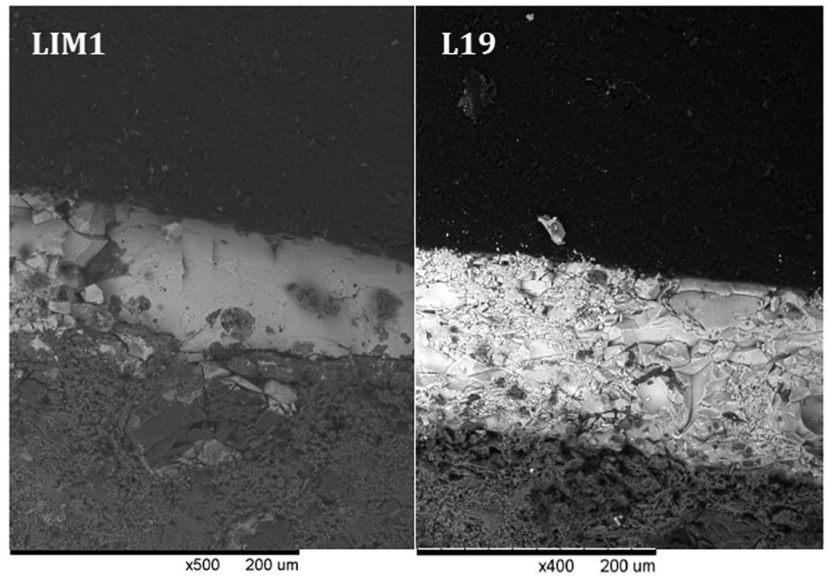

Fig. 1 SEM images acquired on thin sections corresponding to the analysed samples LIM1 and L19.

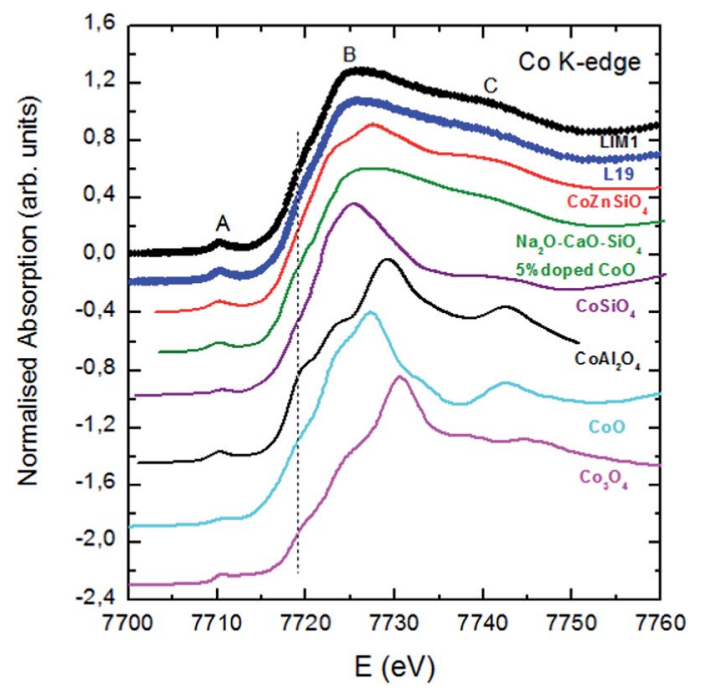

Fig. 2 Comparison of Co K-edge XANES spectra of the blue pigments in $\mathrm{L} 19$ and LIM1 samples, and $\mathrm{CoZnSiO}_{4}, \mathrm{Na}_{2} \mathrm{O}-\mathrm{CaO}-4 \mathrm{SiO}_{4} 5 \% \mathrm{CoO}$ doped, $\mathrm{CoSiO}_{4}, \mathrm{CoAl}_{2} \mathrm{O}_{3}, \mathrm{CoO}, \mathrm{CO}_{3} \mathrm{O}_{4}$ spectra as references.

\section{XAS study on the blue pigment}

2.1 Co K-edge. The Co K-edge XANES spectra are shown in Fig. 2, together with some references, as indicated in the caption.

LIM1 and L19 spectra present the same shape. The main characteristics are a sharp pre-peak, labelled A, and a broad white line, B, followed by a hump-like feature C. The low detailed structures indicate the poor crystalline quality of the Co environment. The FT of the EXAFS signals is shown in Fig. 3. For both cases, it consists of only a peak at $1.6 \AA$, corresponding to the first coordination shell. Due to the low crystallinity of the samples, further peaks are not found. The signals were fitted to a first $\mathrm{Co}-\mathrm{O}$ shell. The interatomic distances, coordination numbers and Debye-Waller factors obtained from the best fits, are reported in Table 1 . The fitting parameter $R$-factor (not shown) demonstrated the quality of the fits.

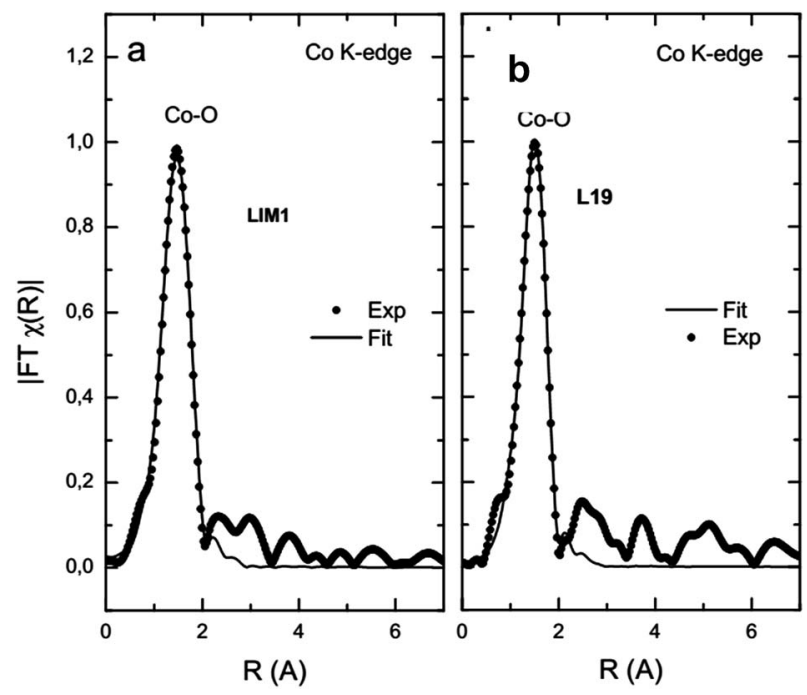

Fig. 3 Moduli of the Fourier transform (dots = experimental signals; line $=$ fits) for the blue pigment in (a) LIM1 and (b) L19 samples at the Co $\mathrm{K}$-edge of the first coordination shell, fitting range: $1 \leq R \leq 2$.

The energy edge for both L19 and LIM1 samples is at 7718 $\mathrm{eV}$, corresponding to a $\mathrm{Co}^{2+}$ oxidation state. Previous results for similar samples ${ }^{34}$ suggested the presence of $\mathrm{Co}_{3} \mathrm{O}_{4}$ and $\mathrm{CoO}$ in the blue pigment. Because $\mathrm{Co}_{3} \mathrm{O}_{4}$ is a mixed valence compound, containing $\mathrm{Co}^{2+}$ and $\mathrm{Co}^{3+}$ ions, it does not seem to be significantly present in any of the analysed samples. On the other hand, we cannot exclude the presence of CoO. However, the comparison of the XANES profiles (see Fig. 2) indicates that the main contribution to the L19 and LIM1 spectra cannot arise from that compound. This is clear due to the lack of the prepeak A and for the shifted position of peak B. Indeed, the relatively intense pre-peak $\mathrm{A}$ indicates that $\mathrm{Co}^{2+}$ is in tetrahedral sites (or in a highly distorted octahedron). That would be expected, because previous studies about the blue pigmenting properties of Co ions had already established that the blue colour is due to tetrahedral $\mathrm{Co}^{2+}$ compounds. ${ }^{35}$ In Fig. 2, some crystalline references of several $\mathrm{Co}^{2+}$ compounds frequently used for pigmentation have been included: $\mathrm{CoZnSiO}_{4},{ }^{36}$ $\mathrm{CoAl}_{2} \mathrm{O}_{4}$ and $\mathrm{CoSiO}_{3} \cdot{ }^{37}$ For further information, we have added the spectrum of $\mathrm{Na}_{2} \mathrm{O}-\mathrm{CaO}-4 \mathrm{SiO}_{4} 5 \% \mathrm{CoO}$ doped (labelled as $\mathrm{NaCa}){ }^{36}$ In $\mathrm{CoZnSiO}_{4}, \mathrm{CoAl}_{2} \mathrm{O}_{4}$ and $\mathrm{NaCa}$, the Co ions are located at tetrahedral sites, while in $\mathrm{CoSiO}_{3}$ the structure around Co corresponds to a distorted octahedron. The spectral profiles of L19 and LIM1 samples look very similar to those of $\mathrm{CoZnSiO}_{4}$, and particularly to the one of NaCa. The similarity of

Table 1 Best fit parameters obtained from the analysis of the first shell contribution of the Co K-edge EXAFS spectra: N coordination number; $r$ distances; $\sigma^{2}$ Debye-Waller factor. Filtering range: $2.5 \leq k \leq 11.7 \AA^{-1}$. Fitting range: $1 \leq R \leq 2$

\begin{tabular}{lllrl}
\hline Sample & Coord. & \multicolumn{1}{l}{$N$} & \multicolumn{1}{l}{$r(\AA)$} & \multicolumn{1}{l}{$\sigma^{2}\left(\AA^{2}\right)$} \\
\hline L19 & Co-O & $3.8 \pm 0.1$ & $1.97 \pm 0.01$ & $0.005 \pm 0.001$ \\
LIM1 & Co-O & $3.5 \pm 0.4$ & $2.1 \pm 0.01$ & $0.006 \pm 0.002$
\end{tabular}


the spectra strongly suggests that Co ions are in an analogous tetrahedral compound. On the other hand, a simultaneous contribution of $\mathrm{CoAl}_{2} \mathrm{O}_{4}$ and $\mathrm{CoSiO}_{3}$ could lead to a similar spectral shape, which is reasonable, because the presence of $\mathrm{Si}$ and $\mathrm{Al}$ in both samples has been previously proved. ${ }^{30}$

The interatomic distances and coordination numbers obtained from the best fit of the EXAFS signals (Table 1) coincide with previous results obtained for systems with Co in tetrahedral coordination. ${ }^{34,38}$ In the case of LIM1, the Co-O bond distances are slightly bigger, but still comparable to the reported results. ${ }^{39}$ This increase could be also due to a higher contribution of $\mathrm{Co}^{2+}$ ions in octahedral sites (nominally larger than those in tetrahedral sites) that would be higher in the Hispano-Moorish LIM1 than in the Italian L19 sample. It is important to note that these findings are different from what was found by other authors, ${ }^{34}$ who studied old Sicilian shards (from Caltagirone site), and in which the blue pigments were found to be related to $\mathrm{CoO}$ and $\mathrm{Co}_{3} \mathrm{O}_{4}$. In any case, our findings do not confirm important differences between the cobalt compounds forming the blue pigments under investigation, indicating an affinity between the Hispano-Moorish and Italians with regard to the materials used in the ceramic production. Probably, this was facilitated by the active commercial exchanges and contacts between them at that time.

2.2 Ni K-edge. The Ni K-edge XANES spectra are shown in Fig. 4. The spectrum of $\mathrm{NiO}$ is also included. As expected, the samples are not crystalline and so their spectral shapes are not very sharp or defined. The FT of the EXAFS signals are shown in Fig. 5, and the interatomic distances, coordination numbers and Debye-Waller factors obtained from the best fits are reported in Table 2. The fitting parameter $R$-factor (not shown) demonstrates the quality of the fits.

The XANES signals are again identical for both samples. Considering the position of the energy edge at $8344 \mathrm{eV}$ and the spectral features, it is most likely to correspond to an amorphous NiO. The fits of the EXAFS signals (Fig. 5) support this, as the obtained coordination numbers and interatomic distances clearly match those of NiO (Table 2). In this case, the EXAFS

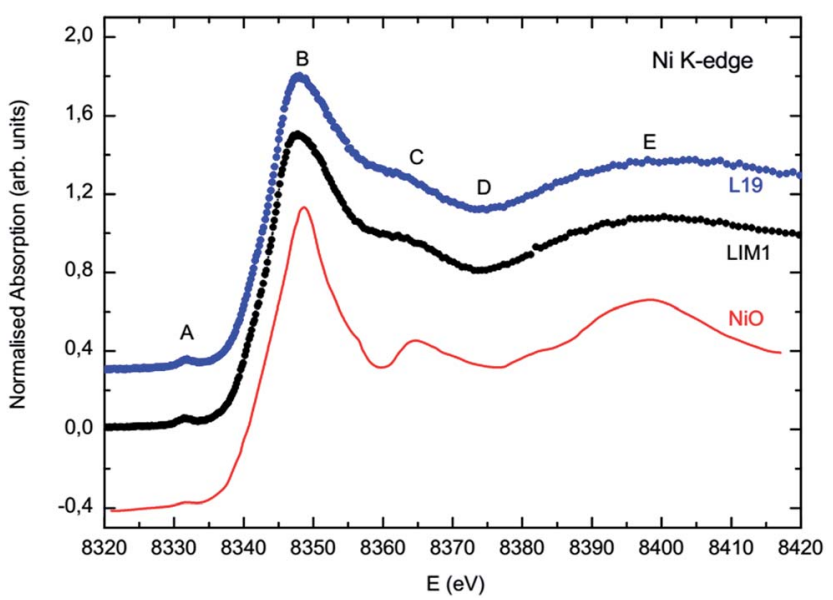

Fig. 4 Ni K-edge XANES spectra of the L19 and LIM1 samples, and NiO reference.

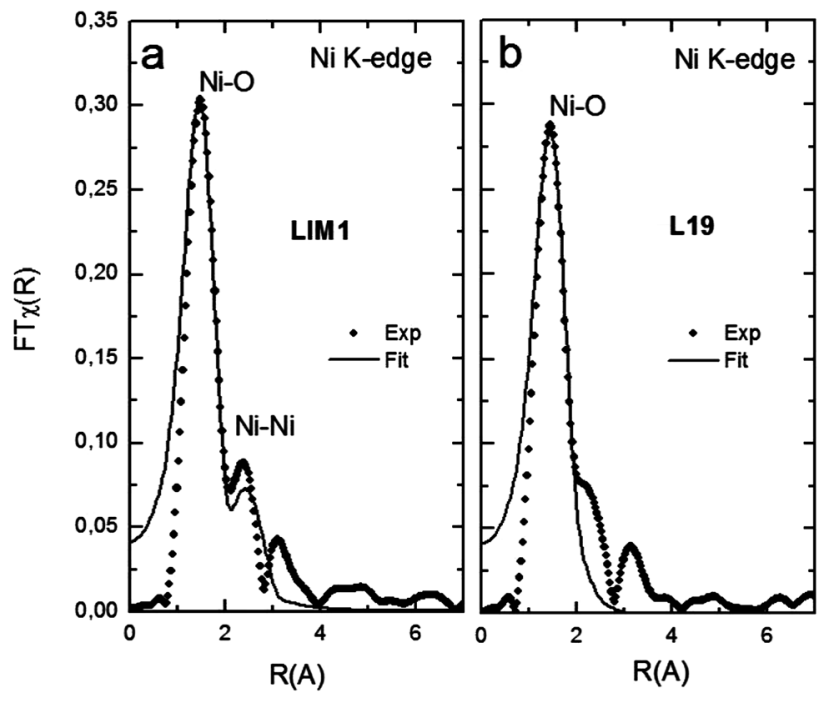

Fig. 5 Moduli of the Fourier transform (dots for experimental signals, line for fits) for the blue pigment in (a) LIM1 and (b) L19 samples at the Co K-edge of the first coordination shell, fitting range: $1 \leq R \leq 2.8 \AA$ and $1 \leq R \leq 2.1 \AA$, respectively.

signals are different for the Italian and the Hispano-Moorish samples. While the module of the FT of the L19 spectrum displays only a peak, corresponding to the first NiO bonds, and a second peak is hinted in the LIM1, that second peak at $2.4 \AA$ is enhanced. This second feature can be attributed to $\mathrm{Ni}-\mathrm{Ni}$ bonds, hence in the LIM1 sample the NiO structure is ordered up to the second coordination shell (Ni-O-Ni).

2.3 Cu K-edge. Finally, the $\mathrm{Cu}$ K-edge signals was measured on the blue pigments present on both samples, that in some parts were covered with lustre and the results are presented in Fig. 6a. $\mathrm{CuO}, \mathrm{Cu}_{2} \mathrm{O}$ and metallic $\mathrm{Cu}$ references are added for comparison. The spectral profiles and the position of the edge indicate that copper is close to the $\mathrm{Cu}^{2+}$ oxidised form. However, the small modifications of the edge and preedge could entail a started reduction of the $\mathrm{Cu}$ ions (similar structures in reduced $\mathrm{CuO}$ have been reported by several authors ${ }^{\mathbf{4 0}}$ ). The EXAFS signals and the magnitude of the FT show that the $\mathrm{Cu}$ environments present short range order in all cases, and just the contribution of the first $\mathrm{Cu}-\mathrm{O}$ bonds is appreciable. The EXAFS contribution of this shell was isolated by Fourier filtering in the range from $0.8 \leq R \leq 2 \AA$, and then

Table 2 Best fit parameters at the Ni K-edge: $N$ coordination number; $r$ distances; $\sigma^{2}$ Debye-Waller factor. Filtering range: $1 \leq k \leq 8.7 \AA^{-1}$. For L19 the analysis corresponds to the first shell (fitting range: $1 \leq R \leq$ 2.1). For LIM1 the best results are obtained by including a second shell (fitting range: $1 \leq R \leq 2.8$ )

\begin{tabular}{lllll}
\hline Sample & Coord. & $N$ & $r(\AA)$ & $\sigma^{2}\left(\AA^{2}\right)$ \\
\hline NiO & Ni-O & 6 & 2.08 & \\
& Ni-Ni & 12 & 2.95 & \\
LIM1 & Ni-O & $5.3 \pm 1.0$ & $2.06 \pm 0.01$ & $0.007 \pm 0.007$ \\
& Ni-Ni & $10.5 \pm 1.0$ & $3.06 \pm 0.04$ & $0.029 \pm 0.006$ \\
L19 & Ni-O & $5.3 \pm 1.0$ & $2.04 \pm 0.03$ & $0.011 \pm 0.008$
\end{tabular}




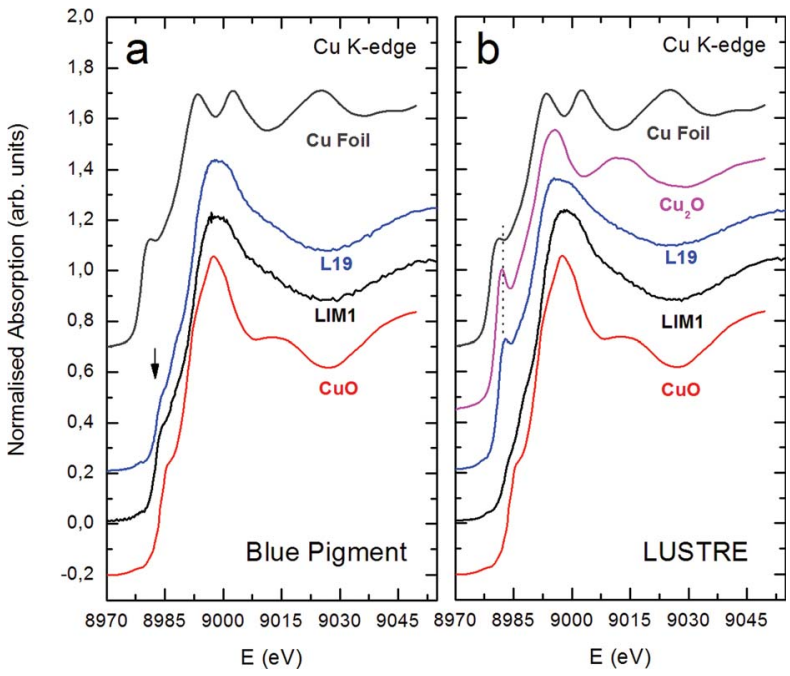

Fig. 6 CuK-edge XANES spectra of $\mathrm{CuO}, \mathrm{Cu}_{2} \mathrm{O}$, metallic $\mathrm{Cu}$ foil and of LIM1 and L19 on the blue pigment (a) and on the lustre (b).

analysed. The results of the fits are shown in Fig. 7a and the best parameters are summarized in Table 3. As expected, the interatomic $\mathrm{Cu}-\mathrm{O}$ resulting distances are similar to the nominal values in $\mathrm{CuO}$.

\section{XAS study of the lustre}

The study of the lustre was focused on the Cu K-edge. XANES spectra recorded at lustre are shown in Fig. 6b. The EXAFS signals were also measured and the moduli of the FT consist only in one peak; just the contribution of the first $\mathrm{Cu}-\mathrm{O}$ bonds is appreciable. The EXAFS contribution of this shell was isolated by Fourier filtering in the range from $0.8 \leq R \leq 2 \AA$. The filtered signals and the results of the fits are shown in Fig. $7 \mathrm{~b}$ and the best parameters are summarized in Table 3 .

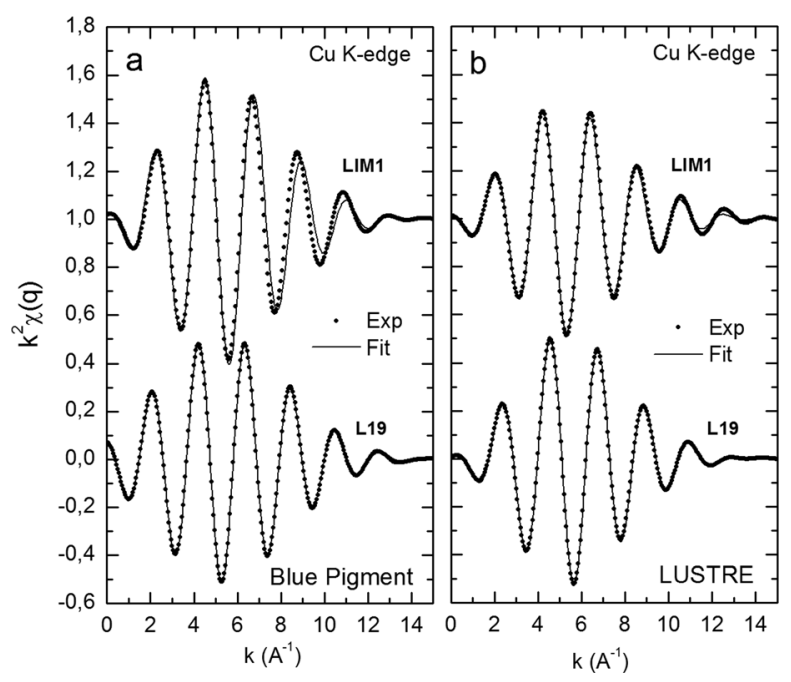

Fig. $7 \quad k^{2}$-weighted filtered EXAFS data (dots) and best fit obtained with parameters included in Table 3 (line) of the (a) blue pigment and (b) lustre in LIM1 and L19 samples, respectively.
Table 3 Best fit parameters obtained from the analysis of the first shell contribution of the Cu K-edge EXAFS spectra: N coordination number; $r$ interatomic distances; $\sigma^{2}$ Debye-Waller factor. Filtering range: $2.5 \leq$ $k \leq 10.7 \AA^{-1}$. Fitting range: $0.8 \leq R \leq 2$

\begin{tabular}{lllll}
\hline Sample & Coord. & $N$ & $r(\AA)$ & $\sigma^{2}\left(\AA^{2}\right)$ \\
\hline $\mathrm{CuO}$ & $\mathrm{Cu}-\mathrm{O}$ & 4 & 1.95 & \\
$\mathrm{Cu}{ }_{2} \mathrm{O}$ & $\mathrm{Cu}-\mathrm{O}$ & 2 & 1.84 & \\
LIM1 blue & $\mathrm{Cu}-\mathrm{O}$ & $3.5 \pm 0.4$ & $1.92 \pm 0.01$ & $0.006 \pm 0.002$ \\
L19 blue & $\mathrm{Cu}-\mathrm{O}$ & $3.8 \pm 0.1$ & $1.93 \pm 0.01$ & $0.001 \pm 0.002$ \\
LIM1 lustre & $\mathrm{Cu}-\mathrm{O}$ & $3.5 \pm 0.4$ & $1.92 \pm 0.01$ & $0.006 \pm 0.002$ \\
L19 lustre & $\mathrm{Cu}-\mathrm{O}$ & $3.2 \pm 0.1$ & $1.84 \pm 0.01$ & $0.005 \pm 0.003$
\end{tabular}

The XANES spectra registered in the lustred regions of both samples display significant differences: the L19 XANES spectrum presents the characteristic pre-peak and energy edge (8981 $\mathrm{eV}$ ) of $\mathrm{Cu}_{2} \mathrm{O}$. On the other hand, the spectrum of LIM1 does not show the pre-peak, and the position of the energy edge, at 8983 $\mathrm{eV}$, is in this case closer to CuO. Anyhow, the differences in the edge indicate as well, a started reduction of the $\mathrm{Cu}$ ions.

In agreement with the previous discussion, the obtained $\mathrm{Cu}-$ O interatomic distance found in the L19 sample is the same as that of $\mathrm{Cu}_{2} \mathrm{O}$, whereas in the LIM1 sample the result matches the one of $\mathrm{CuO}$.

Our results for the Italian L19 sample are in agreement with previous work concerning similar samples from the Italian Renaissance. ${ }^{41}$ Those studies reported the presence of metallic $\mathrm{Cu}$ in the very near surface region of the lustre; however, in our case, when XAS measurements were performed in fluorescence mode, the results pointed out the presence of $\mathrm{Cu}_{2} \mathrm{O}$. The different outcome is due to the deeper sampling probing achieved by the fluorescence mode (about $30 \mu \mathrm{m}$ ), not so sensible to the near surface zone. At the first step of the formation of lustre, copper ions would migrate from the initial lustre paste to the glaze, and after the ion penetration into the glaze. A reduction to metal $\mathrm{Cu}$ nanoparticles is expected, as a consequence of the reducing atmosphere created in the kiln. Therefore, the amount of reduced metallic copper would be distributed in the region near the surface, whereas at the deeper regions the $\mathrm{Cu}$ ions would be mostly in oxidized form. However, the results of the HispanoMoorish LIM1 sample indicate a less reduced state of $\mathrm{Cu}$ ions, similar to that found for $\mathrm{Cu}$ ions in the blue part. Considering all, it seems feasible that the dispersion of $\mathrm{Cu}$ ions into the glaze occurred at a different efficiency for the L19 and the LIM1 samples, respectively. In this case, an interpretation could be made considering the use of different technological procedures generating different efficiency in the reducing phase and consequently generating copper ions in different oxidation states.

Table 4 Elemental composition by ETAAS: * in ref. 3; ** in ref. 25; *** in ref. 26

\begin{tabular}{llll}
\hline Sample & $\mathrm{Cu} / \mathrm{Ag}$ & $\mathrm{Ag} / \mathrm{Cu}$ & $\mathrm{Bi} / \mathrm{Ag}$ \\
\hline L19 & $9.17^{*}$ & 0.11 & $5.6^{* * *}$ \\
LIM1 & $89.90^{* * *}$ & 0.011 & -*** $^{* *}$
\end{tabular}


In Table 4, the chemical composition of the analysed shards is reported; it is possible to note that they present great differences with regard to $\mathrm{Cu} / \mathrm{Ag}$ ratios and the chemical composition certainly influences the reduction process. As well, the bismuth reported in Table 4 confirms its use only in the Italian production. $^{25-30}$ It is not possible to generalize its use as reducing agent, because it is not present at all in the HispanoMoorish production, and is found as cosalite in the Italian production. In this compound the Bi oxidation state is +3 , thus it is not present in its oxidized form, which would be indicative of its reducing activity.

\section{Conclusions}

In this work, two lustred majolica shards, from HispanoMoorish (LIM1) and Italian (L19) productions, were studied in two different regions: on the blue pigment and on the lustre.

On the blue pigment, XAS spectra were measured at the Co, $\mathrm{Ni}$ and $\mathrm{Cu}$ K-edge. Concerning the Co, for both productions the XANES spectra pointed out the poor crystallinity of the Co environment as well as a main contribution of $\mathrm{Co}^{2+}$ ions at tetrahedral sites. Besides, the analysis of the EXAFS signals show values of Co-O interatomic distances in agreement with the conclusions of the XANES. In the case of the HispanoMoorish LIM1 sample, those distances are slightly higher, indicating a higher contribution of $\mathrm{Co}^{2+}$ at octahedral sites. The blue pigmentation could be due to a compound analogous to $\mathrm{Na}_{2} \mathrm{O}-\mathrm{CaO}-4 \mathrm{SiO}_{4} 5 \% \mathrm{CoO}$ doped or to the contribution of both $\mathrm{CoAl}_{2} \mathrm{O}_{4}$ and $\mathrm{CoSiO}_{3}$. Ni is present as $\mathrm{NiO}$ but some differences arise between the two samples. In fact, despite the sample being amorphous, as expected, in LIM1 the NiO structure is ordered up to the second coordination shell (Ni-O-Ni). The Cu spectra in the blue parts are quite similar, and indicate that $\mathrm{Cu}$ is close to $\mathrm{Cu}^{+2}$, even though it is possible to observe, for both samples, an edge modification that suggest a started reduction of the $\mathrm{Cu}$ ions.

With respect to lustre, significant differences have been observed when the $\mathrm{Cu}$ XANES spectra are compared: L19 has a behaviour matching $\mathrm{Cu}_{2} \mathrm{O}$. The behavior of LIM1 matches CuO, indicating for this sample, a lower degree of reduction. In this case, an interpretation could be made on the basis of the different technological processes used, producing at last, copper ions in different oxidation states.

\section{Acknowledgements}

M. Hunault, (Université Pierre et Marie Curie - Paris 6), Paris, J. Perez-Arantegui (University of Zaragoza), A. Longo (ISMN-CNR, Palermo) and M. P. Casaletto (ISMN-CNR, Palermo) are kindly acknowledged for helpful discussions. Gubbio Town Council is kindly acknowledged for having supplied the analysed samples.

\section{Notes and references}

1 I. Borgia, B. Brunetti, I. Mariani, A. Sgamellotti, F. Cariati, P. Fermo, M. Mellini, C. Viti and G. Padeletti, Appl. Surf. Sci., 2002, 185, 206.
2 P. Fermo, F. Cariati, C. Cipriani, M. Canetti, G. Padeletti, B. Brunetti and A. Sgamellotti, Appl. Surf. Sci., 2002, 185, 309.

3 G. Padeletti and P. Fermo, Appl. Phys. A: Mater. Sci. Process., 2003, 76, 515.

4 G. Padeletti and P. Fermo, Appl. Phys. A: Mater. Sci. Process., 2004, 79, 241.

5 A. Galli, M. Martini, E. Sibilia, G. Padeletti and P. Fermo, Appl. Phys. A: Mater. Sci. Process., 2004, 79, 293.

6 G. Padeletti and P. Fermo, Techné, 2004, 20, 35.

7 S. Berthier, G. Padeletti, P. Fermo, A. Bouquillon, M. Acouturier, E. Charron and V. Reillon, Appl. Phys. A, 2006, 83, 573.

8 G. Padeletti and P. Fermo, J. Nanosci. Nanotechnol., 2012, 12, 8764.

9 P. Fermo and G. Padeletti, Appl. Phys. A: Mater. Sci. Process., 2013, 113, 825.

10 T. Pradell, R. S. Pavlov, P. C. Gutiérrez, A. Climent-Font and J. Molera, J. Appl. Phys., 2012, 112, 054307.

11 G. Molina, M. S. Tite, J. Molera, A. Climent-Font and T. Pradell, J. Eur. Ceram. Soc., 2014, 34, 2563.

12 T. Pradell, J. Molera, C. Bayés and P. Roura, Appl. Phys. A: Mater. Sci. Process., 2006, 83, 203.

13 T. Pradell, J. Molera, A. D. Smith and M. S. Tite, J. Archaeol. Sci., 2008, 35, 1201.

14 J. Pérez-Arantegui, J. Molera, A. Larrea, T. Pradell, M. Vendrell-Saz, I. Borgia, B. G. Brunetti, F. Cariati, P. Fermo, M. Mellini, A. Sgamellotti and C. Viti, J. Am. Ceram. Soc., 2001, 84, 442.

15 J. Roqué, J. Molera, J. Pérez-Arantegui, C. Calabuig, J. Portillo and M. Vendrell-Saz, Archaeometry, 2007, 49, 511.

16 J. Pérez-Arantegui and A. Larrea, Trends Anal. Chem., 2003, 22, 327.

17 P. Colomban, J. Nano Res., 2009, 8, 109.

18 S. Padovani, D. Puzzovio, C. Sada, P. Mazzoldi, I. Borgia, A. Sgamellotti, B. G. Brunetti, L. Cartechini, F. D'Acapito, C. Maurizio, F. Shokoui, P. Oliaiy, J. Rahighi, M. LamehiRachti and E. Pantos, Appl. Phys. A: Mater. Sci. Process., 2006, 83, 521.

19 A. Smith, T. Pradell, J. Roqué, J. Molera, M. Vendrell-Saz, A. J. Dent and E. Pantos, J. Non-Cryst. Solids, 2006, 352, 5353.

20 F. Gonella and P. Mazzoldi, Handbook of Nanostructured Materials and Nanotechnology, ed. H. S. Nalwa, Academic, San Diego, 2000, vol. 4.

21 U. Kreibig, M. Vollmer, Optical properties of Metal Clusters, Springer, Berlin, 1995.

22 G. Padeletti, G. M. Ingo, A. Bouquillon, S. Pages-Camagna, M. Aucouturier, S. Roehrs and P. Fermo, Appl. Phys. A: Mater. Sci. Process., 2006, 83, 475.

23 G. Padeletti, Ceramics Art and Perspection, 2006, 64, 44.

24 G. Padeletti, G. M. Ingo, A. Bouquillon, M. Aucouturier, M. L. de Rochebrune and F. Barbe, in Mastro Giorgio da Gubbio - Art, Science and Technology of Lustred Majolicas, Volumnia, 2013, pp. 151-174.

25 G. Padeletti and P. Fermo, Appl. Phys. A: Mater. Sci. Process., 2003, 77, 125.

26 G. Padeletti and P. Fermo, Appl. Phys. A: Mater. Sci. Process., 2004, 79, 277. 
27 D. Cabanne, A. Bouquillon, M. Aucouturier, X. Dector and G. Padeletti, Appl. Phys. A: Mater. Sci. Process., 2008, 92, 11.

28 G. Padeletti, P. Fermo, A. Bouquillon, M. Aucouturier and F. Barbe, Appl. Phys. A: Mater. Sci. Process., 2010, 100, 747.

29 G. Padeletti and P. Fermo, Appl. Phys. A: Mater. Sci. Process., 2010, 100, 771.

30 G. Padeletti, P. Fermo, A. Bouquillon, M. Aucouturier and F. Barbe, on Mastro Giorgio da Gubbio - Art, Science and Technology of Lustred Majolicas, Volumnia, 2013, pp. 175196.

31 A. Di Cicco, G. Aquilanti, M. Minicucci, E. Principi, N. Novello, A. Cognigni and L. Olivi, J. Phys.: Conf. Ser., 2009, 190, 012043.

32 G. Bunker, Introduction to XAFS, Cambridge University Press, 2010.

33 B. Ravel and M. Newville, J. Synchrotron Radiat., 2005, 12, 537.
34 D. Barilaro, V. Crupi, S. Interdonato, D. Majolino, V. Venuti, G. Barone, M. F. la Russa and F. Bardelli, Appl. Phys. A: Mater. Sci. Process., 2008, 92, 91.

35 T. Minami and S. Ghosh, Curr. Sci., 2000, 78, 892.

36 M. Hunault, G. Calas, L. Galoisy, G. Lelong and M. Newville, J. Am. Ceram. Soc., 2014, 97, 60.

37 H. Wang, et al., J. Catal., 2013, 300, 91.

38 L. Wang and C. Wang, J. Anal. At. Spectrom., 2011, 26, 1796. 39 M. O. Figueiredo, T. P. Silva, J. P. Veiga, M. I. Prudencio, M. I. Dias, M. A. Matos and A. M. Pais, in LASMAC \& IMRC 2009-Selected papers 2010, 2010, vol. 84-88.

40 J. Y. Kim, J. A. Rodriguez, J. C. Hanson, A. I. Frenkel and P. L. Lee, J. Am. Chem. Soc., 2003, 125, 10685.

41 S. Padovani, I. Borgia, B. Brunetti, A. Sgamellotti, A. Giulivi, F. D'Acapito, P. Mazzoldi, C. Sada and G. Battaglin, Appl. Phys. A: Mater. Sci. Process., 2004, 79, 229. 